\title{
Contribution of Laparoscopy in the Management of Female Infertility in Low Resource Countries: A Review of 208 Cases at the Yaoundé General Hospital, Cameroon
}

\author{
Jean Dupont Kemfang Ngowa ${ }^{1,2}{ }^{*}$, Jean Marie Kasia ${ }^{1,2}$, Victorine Nkongo ${ }^{1}$, Anny Ngassam $^{2}$, \\ Jovanny Fouogue Tsuala1, Philemon Nsem¹, Alexis Medou ${ }^{3}$ \\ ${ }^{1}$ Department of Obstetrics and Gynaecology, Faculty of Medicine and Biomedical Sciences, \\ University of Yaoundé I, Yaoundé, Cameroon \\ ${ }^{2}$ Gynecological Endoscopic Surgery and Human Reproductive Teaching Hospital, Yaoundé, Cameroon \\ ${ }^{3}$ Anesthesia Unit, Yaoundé General Hospital, Yaoundé, Cameroon \\ Email: "jdkemfang@yahoo.fr
}

Received 14 November 2015; accepted 22 December 2015; published 25 December 2015

Copyright $@ 2015$ by authors and Scientific Research Publishing Inc.

This work is licensed under the Creative Commons Attribution International License (CC BY). http://creativecommons.org/licenses/by/4.0/

(c) (i) Open Access

\section{Abstract}

Background: Infertility is a global problem, but the highest prevalence is in low resource countries, particularly in sub-Saharan Africa where tubal damage following pelvic infection is the commonest cause. Objectives: This study aimed to assess contribution of laparoscopy as a diagnostic and therapeutic tool in infertile women in our setting. Methods: A descriptive review of complete medical records of 208 women who underwent laparoscopy at the Gynaecology Unit of Yaoundé General Hospital from December 2007 to December 2012. Results: Two hundred and eight women were enrolled in this study. Mean age was $32.6 \pm 11.25$ years. Infertility was secondary in $71.6 \%$ of cases; $125(60.1 \%)$ women were married and $116(55.8 \%)$ had a positive serology of Chlamydia trachomatis infection. The most frequent findings during diagnostic laparoscopy were: pelvic adhesions $(83.7 \%)$, hydrosalpinx (21.6\%), pyosalpinx (4.8\%), perihepatic adhesions $(25.5 \%)$, uterine fibromas (22.6\%), pelvic endometriosis (13\%) and ovarian abnormalities (10.1\%). The surgical procedures during laparoscopy were: adhesiolysis $(79.7 \%)$, tuboplasty $(35.0 \%)$, salpingectomy (8.2\%), ovarian cystectomy $(5.8 \%)$ and myomectomy $(1.9 \%)$. Three $(1.4 \%)$ cases of uterine perforation and $1(0.5 \%)$ case of laparoscopy conversion to laparotomy were observed. Conclusion: Diagnostic laparoscopy revealed that tubal lesions and pelvic adhesions were still the major causes of female infertility in developing countries. Adhesiolysis and tuboplasty were the most frequently performed surgical procedures during laparoscopy. Therefore, training in endoscopic

${ }^{*}$ Corresponding author.

How to cite this paper: Ngowa, J.D.K., et al. (2015) Contribution of Laparoscopy in the Management of Female Infertility in Low Resource Countries: A Review of 208 Cases at the Yaoundé General Hospital, Cameroon. International Journal of Clinical Medicine, 6, 934-939. http://dx.doi.org/10.4236/ijcm.2015.612122 
surgery should be regarded as an important issue in developing countries.

Keywords

Laparoscopy, Infertility, Pelvic Adhesions, Adhesiolysis, Tuboplasty, Myomectomy

\section{Background}

Infertility is a global problem, but the highest prevalence is in low resource countries, particularly in sub-Saharan Africa where tubal damage following pelvic infection is the commonest cause [1]. In Africa, tubal damage contributes about $42 \%$ to $77 \%$ of tubal infertility [2]. Laparoscopy has become an integral part of gynecologic surgery for the diagnosis and treatment of abdomino-pelvic disorders of the female genital tract [3]. Laparoscopy is perceived as a minimally invasive surgical technique that provides a panoramic and magnified view of the pelvic organs and allows surgery at the time of diagnosis [3]. Gynaecological surgical laparoscopy was introduced in Cameroon in the early 1990s at the Yaoundé General Hospital [4]. However, previous studies in low resource countries reported that infertility was the main indication for gynaecological laparoscopy [5]-[7]. Operative procedures, such as lysis of adhesions, ablation of endometriosis, tuboplasty and salpingectomy for hydrosalpinx or pyosalpinx at the time of laparoscopy can enhance conception, naturally or with intra uterine insemination or in vitro fertilization [3] [8]. The aim of this study is to evaluate the contribution of laparoscopy as a diagnostic and therapeutic tool in infertile women in our setting.

\section{Methods}

We carried out a cross-sectional study based on medical records of 208 women followed up for infertility at the Obstetrics and Gynecology Unit of the Yaoundé General Hospital (YGH) in Cameroon from December 2007 to December 2012. We included medical records of infertile women managed by laparoscopy during the study period. We obtained approval from the medical committee of the YGH to conduct this study. Diagnostic and/or operative laparoscopy was performed in the operating theatre under general anesthesia, during the follicular phase of the menstrual cycle before the ovulatory period. During the diagnostic laparoscopy, inspection of the pelvis (genital organs) and the liver was performed, followed by testing for tubal patency using methylene blue injected through the cervix via a Novak cannula. The presence of adhesions, structural abnormalities of the uterus, endometriosis and fallopian tube lesions were sought for. When necessary, operative laparoscopic procedures were performed (adhesiolysis, tuboplasty, cystectomy, myomectomy, salpingectomy, ablation of endometriotic lesions).

Data collection included, socio-demographic characteristics (age, marital status, religion and occupation), clinical and paraclinical parameters, findings during diagnostic laparoscopy and various operative procedures. Operative complications were also registered. Data was analyzed using Microsoft Excel ${ }^{\circledR}$ (version 2010) software. Descriptive statistical analysis was performed.

\section{Results}

Two hundred and eight women with a history of infertility who underwent laparoscopy were included in this study. Table 1 shows the general characteristics of these patients. The mean age of the patients was $31.4 \pm 6.4$ years (range from 19 to 44 years). Secondary infertility was more frequent (71.6\%) than primary infertility (28.4\%) and married women were the most represented (60.1\%).

Table 2 shows the clinical characteristics of the study population. More than half of the women presented with chronic pelvic pain (55.8\%) and positive Chlamydia trachomatis serology (55.8\%).

Table 3 shows the distribution of patients in respect with findings during diagnostic laparoscopy. Pelvic adhesions (83.7\%), tubal obstruction (44.2\%), tubal distension (26.4\%) by hydrosalpinx or pyosalpinx, peri-hepatic adhesions (25.5\%) and uterine fibroids (22.2\%) were the most frequent lesions observed during diagnostic laparoscopy. Peritoneal endometriosis was also found in $13 \%$ of cases. 
Table 1. General characteristics of patients $(n=208)$.

\begin{tabular}{|c|c|c|}
\hline Characteristics & $n$ & $\%$ \\
\hline \multicolumn{3}{|l|}{ Age range (years) } \\
\hline $15-25$ & 18 & 8.7 \\
\hline $26-35$ & 129 & 62.0 \\
\hline $36-45$ & 61 & 29.3 \\
\hline \multicolumn{3}{|l|}{ Profession } \\
\hline House wife & 82 & 39.4 \\
\hline Worker & 102 & 49.1 \\
\hline Student & 24 & 11.5 \\
\hline \multicolumn{3}{|l|}{ Marital Status } \\
\hline Single & 83 & 39.9 \\
\hline Married & 125 & 60.1 \\
\hline \multicolumn{3}{|l|}{ Type of infertility } \\
\hline Primary infertility & 59 & 28.4 \\
\hline Secondary infertility & 149 & 71.6 \\
\hline
\end{tabular}

Table 2. Clinical characteristics of the study population; $n=208$.

\begin{tabular}{lcc}
\multicolumn{1}{c}{ Characteristics } & $\boldsymbol{n}$ & \% \\
\hline History of chronic pelvic pain & 116 & 55.8 \\
History of dyspareunia & 63 & 30.3 \\
Past history of pelvic inflammatory disease & 115 & 55.3 \\
Positive serology of Chlamydia trachomatis & 116 & 55.8 \\
Past history of pelvic surgery & & 16.8 \\
$\quad{ }^{*}$ Annexal surgery & 35 & 18.4 \\
$\quad$ Myomectomy & 38 & 3.8 \\
\hline$* *$
\end{tabular}

"Tuboplasty/salpingectomy/ovarian cystectomy; ${ }^{* *}$ Appendectomy/cesarean section.

Table 3. Distribution of patients in respect with findings at laparoscopy; $n=208$.

\begin{tabular}{lcc}
\hline \multicolumn{1}{c}{$\quad$ Laparoscopic findings } & $\boldsymbol{n}$ & $\%$ \\
\hline No pelvic lesion & 4 & 2.0 \\
Pelvic adhesions & 174 & 83.7 \\
Peri-hepatic adhesions & 53 & 25.5 \\
Tubal obstruction (one or two sides) & 92 & 44.2 \\
Hydrosalpinx (one or two sides) & 45 & 21.6 \\
Pyosalpinx (one or two sides) & 10 & 4.8 \\
Absence of tube (one or two sides) & 4 & 2.0 \\
Pelvic endometriosis & 27 & 13.0 \\
Ovarian dystrophy and cysts & 21 & 10.0 \\
Uterine fibroids & 47 & 22.6 \\
\hline
\end{tabular}

Table 4 shows the distribution of patients following operative procedures performed during laparoscopy. Adhesiolysis (79.7\%), distal tuboplasty (35.0\%) and ovarian surgery (10.1\%) were the main operative procedures during laparoscopy for infertility. Out of the 74 cases of distal tuboplasty performed, 72 (97.27\%) had 
Table 4. Distribution of patients with respect to operative procedures during laparoscopy.

\begin{tabular}{|c|c|c|}
\hline Operative procedures & $\mathbf{n}$ & $\%$ \\
\hline Adhesiolysis & 165 & 79.7 \\
\hline Distal tuboplasty & 74 & 35 \\
\hline Salpingectomy & 17 & 8.2 \\
\hline Ovarian cystectomy & 12 & 5.8 \\
\hline Ovarian drilling & 9 & 4.3 \\
\hline Myomectomy & 4 & 1.9 \\
\hline Excision of pelvic endometriotic lesions & 2 & 1 \\
\hline
\end{tabular}

tubal patency after surgery. All the four cases of myomectomy performed, were done on sub serous fibromas.

The operative complications found were $3(1.4 \%)$ cases of uterine perforation with the hysterometer used for uterine mobilisation during laparoscopy and $1(0.5 \%)$ case of conversion from laparoscopy to laparotomy, in an obese patient with ovarian cyst.

\section{Discussion}

Exploration of the female genital tract is one of the essential elements of infertility assessment. Laparoscopy provides both a panoramic view of the pelvic reproductive anatomy and a magnified view of pelvic organs and peritoneal surfaces. It is generally regarded as the most reliable tool in the diagnosis of tubal pathology and other intra-abdominal causes of infertility [9] [10]. We reviewed in this study 208 cases of laparoscopy at the Yaoundé General Hospital indicated for female infertility. In previous studies carry out in Cameroon and Senegal, infertility was the most frequent indication for laparoscopy [5] [7] [11]. Adhesions involving the fallopian tube are considered as causes of infertility [12]. Pelvic adhesion (83.7\%) was the most frequent findings at diagnostic laparoscopy in our series. Our result is similar to the one reported by Mboudou et al. who found 71.6\% of tubo-peritoneal adhesions among infertile women who underwent laparoscopy in Yaoundé [7]. However, our result is high than $40.6 \%$ of pelvic adhesions reported by Mbaye et al. among women who underwent laparoscopy at Dakar University Hospital and 33\% of pelvic adhesions reported by Jain et al. among women who underwent laparoscopy for infertility in India [5] [13]. The difference in the prevalence of pelvic adhesions can be explained by the difference in the characteristics of the study population, in the prevalence of sexually transmitted infection and in the frequency of past history of pelvic surgeries between these studies. Tubal factor is the most frequent cause of infertility in Africa [14] [15].

In accordance to previous African studies [5] [7] [11], we found a high frequency of tubal lesions (70.6\%) in this study. Tubo-peritoneal factors of female infertility are mainly due to sexually transmitted infection, postabortum and post-partum infections [16] [17]. In line with literature data, our results showed a high seroprevalence of Chlamydia trachomatis infection (55.8\%) which is closed to $66.2 \%$ reported in one previous study in Yaoundé among infertile women attending gynecological consultations for infertility at the YGH [18].

The peri-hepatic adhesions are part of the Fitz-Hugh-Curtis syndrome found in genital Chlamydia trachomatis and gonoccocal infections [19].

The high prevalence (25.5\%) of peri-hepatic adhesions found in this study during diagnostic laparoscopy is closed to $40 \%$ of peri-hepatic at laparoscopy among infertile women at the Yaoundé Gyneco-Obstetric and Pediatric Hospital reported by Nzintcheu et al. [20]. The high prevalence of Chlamydia trachomatis infection in our study population is the possible explanation of this elevated frequency of the peri-hepatic adhesions during laparoscopy. Hence, in our setting, a lot of emphasis should be laid on developing a solid preventive strategy on female genital tract infections. Especially on prevention of sexually transmitted infections, a prevention of post abortum infection by reduce the unsafe abortion; the promotion of hygienic obstetrics techniques and early recognition and treatment of maternal infections.

The high incidence of endometriosis observed in infertile women has led many investigators and clinicians to the assumption that there is a causal relationship between these two entities [21]. We identified endometriosis in $13.0 \%$ of cases which is close to $9 \%$ reported by Jain et al. in India among infertile women underwent laparoscopy [13]. 
Several authors found an association between the degree of adnexal adhesions and the rate of occurrence of life births after adhesiolysis [12] [22]-[24]. Adhesiolysis (79.7\%) and distal tuboplasty (35\%) were the two most frequent laparoscopic procedures in our series. Our results are similar to those of previous African studies [5] [7].

We found $1.4 \%$ of surgical complications in our series due to uterine perforation during its mobilisation by hysterometer. This result is lower than $2.46 \%$ reported by Tchente et al. in the previous study in Yaoundé. One explanation of the difference of complications can be the fact that Tchente et al. in their study included anesthetic and surgical complications. The main limitation of our study is its retrospective design. However, this study is a contribution to the understanding of the patterns of female infertility in Cameroon.

\section{Conclusion}

Diagnostic laparoscopy reveals that tubal lesions and pelvic adhesions are still the major causes for female infertility in developing countries. Adhesiolysis and tuboplasty are the most frequently performed surgical procedures during laparoscopy indicated for female infertility. Therefore, training in endoscopic surgery should be regarded as an important issue in developing countries. Besides the training in endoscopy surgery, it is urgent to develop a preventive strategy of genital tract infection in our population to reduce the risk of tubo-peritoneal lesions.

\section{Conflict of Interests}

The authors declare that they have no conflict of interest.

\section{References}

[1] Sharma, S., Mittal, S. and Aggarwal, P. (2009) Management of Infertility in Low Resource Countries. BJOG, 116, 7783. http://dx.doi.org/10.1111/j.1471-0528.2009.02311.x

[2] Otolorin, E.O., Ojengbede, O. and Falase, A.O. (1987) Laparoscopic Evaluation of the Tuboperitoneal Factor in Infertile Nigerian Women. International Journal of Gynecology \& Obstetrics, 25, 47-51. http://dx.doi.org/10.1016/0020-7292(87)90183-4

[3] Berker, B., Mahdavi, A., Shahmohamady, B. and Nezhat, C. (2005) Role of Laparoscopic Surgery in Infertility. Middle East Fertility Society Journal, 10, 94-104.

[4] Raiga, J., Kasia, J.M., Canis, M., Glowaczower, E., Doh, A.S. and Bruhat, M.A. (1994) Introduction of Gynecologic Endoscopic Surgery in an African Setting. International Journal of Gynecology \& Obstetrics, 46, 261-264. http://dx.doi.org/10.1016/0020-7292(94)90403-0

[5] Mbaye, M., Cissé, M.L., Guèye, S.M.K., Dièmé, F.M.E., Diouf, A.A., Guèye, M., et al. (2012) Premiers résultats de la coelioscopie gynécologique au Centre hospitalier universitaire (CHU) de Dakar série prospective de 128 cas. Journal of Obstetrics and Gynaecology Canada, 34, 939-946.

[6] Ekwunife, C.N. and Nwobe, O. (2014) First 100 Laparoscopic Surgeries in a Predominantly Rural Nigerian Population: A Template for Future Growth. World Journal of Surgery, 38, 2813-2817. http://dx.doi.org/10.1007/s00268-014-2656-2

[7] Mboudou, E.T., Foumane, P., Morfaw, L.I.F., Minkande, Z., Dohbit, S.J. aand Mbatsogo, E.B.A. (2013) Female Infertility and Laparoscopic Surgery: A Series of 415 Operations at the Yaounde Gyneco-Obstetric and Pediatric Hospital, Cameroon. Open Journal of Obstetrics and Gynecology, 3, 663-667. http://dx.doi.org/10.4236/ojog.2013.39121

[8] Fouany, M.R. and Muasher, S.J. (2010) Is There a Role for Laparoscopy in the Diagnosis and Treatment of Infertility in the 21st Century? Middle East Fertility Society Journal, 15, 146-152. http://dx.doi.org/10.1016/j.mefs.2010.06.011

[9] Tanahatoe, S.J., Hompes, P.G. and Lambalk, C.B. (2003) Investigation of the Infertile Couple. Should Diagnostic Laparoscopy Be Performed in the Infertility Work up Program in Patients Undergoing Intrauterine Insemination? Human Reproduction, 18, 8-11. http://dx.doi.org/10.1093/humrep/deg034

[10] Mol, B.W., Collins, J.A., Burrows, E.A., Van der Veen, F. and Bossuyt, P.M. (1999) Comparison of Hysterosalpingography and Laparoscopy in Predicting Fertility Outcome. Human Reproduction, 14, 1237-1242. http://dx.doi.org/10.1093/humrep/14.5.1237

[11] Tchente Nguefack, C., Mboudou, E., Tejiokem, M.C. and Doh, A. (2009) Les complications de la coeliochirurgie dans le service de gynécologie A de l’hôpital général de Yaoundé au Cameroun. Journal de Gynécologie-Obstétrique et Biologie de la Reproduction, 38, 545-551. http://dx.doi.org/10.1016/j.jgyn.2009.06.008 
[12] Gomel, V. (1983) Salpingo-Ovariolysis by Laparoscopy in Infertility. Fertility and Sterility, 40, 607-611.

[13] Jain, G., Khatuja, R., Juneja, A. and Mehta, S. (2014) Laparoscopy: As a First Line Diagnostic Tool for Infertility Evaluation. Journal of Clinical and Diagnostic Research, 8, Article ID: OC01-2. http://dx.doi.org/10.7860/JCDR/2014/9822.4929

[14] Okunlola, M.A., Adebayo, O.J., Odukogbe, A.A., Morhason-Bello, I.O. and Owonikoko, K.M. (2005) Assessment of Tubal Factor Contribution to Female Infertility in a Low Resource Setting (Southwest Nigeria): Hysterosalpingography vs. Laparoscopy. Journal of Obstetrics and Gynaecology, 25, 803-804. http://dx.doi.org/10.1080/01443610500328348

[15] Steinkeler, J.A., Woodfield, C.A., Lazarus, E. and Hillstrom, M.M. (2009) Female Infertility: A Systematic Approach to Radiologic Imaging and Diagnosis. Radiographics, 29, 1353-1370. http://dx.doi.org/10.1148/rg.295095047

[16] Umeora, O.U., Mbazor, J.O. and Okpere, E.E. (2007) Tubal Factor Infertility in Benin City, Nigeria-Sociodemographics of Patients and Aetio-Pathogenic Factors. Tropical Doctor, 37, 92-94. http://dx.doi.org/10.1258/004947507780609446

[17] Okonofua, F.E., Ako-Nai, K.A. and Dighitoghi, M.D. (1995) Lower Genital Tract Infections in Infertile Nigerian Women Compared with Controls. Genitourinary Medicine, 71, 163-168. http://dx.doi.org/10.1136/sti.71.3.163

[18] Kemfang Ngowa, J.D., Mboudou, E.T., Toukam, M., Ngassam, A. and Kasia, J.M. (2014) Séro-prévalence de l'infection à Chlamydia trachomatis chez les femmes consultant pour infertilité à l'Hôpital Général de Yaoundé. Guinée Médicale, 83, 17-21.

[19] Roy, B.N. and Tulandi, T. (2006) Syndrome de Fitz-Hugh-Curtis. Journal of Obstetrics and Gynaecology Canada, 28, 860.

[20] Nzintcheu Youssa, J.M., Foumane, P., Mboudou, E.T., Nana, P.N., Fomulu, J.N. and Doh, A.S. (2012) Perihepatitis as a Laparoscopic Finding in Infertile Women at the Yaoundé Gyneco-Obstetric and Pediatric Hospital: Prevalence and Correlation with Tubo-Pelvic Lesions. Clinics in Mother and Child Health, 9, 1-5. http://dx.doi.org/10.4303/cmch/C120501

[21] Buyalosa, R.P. and Agarwal, S.K. (2000) Endometriosis-Associated Infertility. Current Opinion in Obstetrics and Gynecology, 12, 377-381. http://dx.doi.org/10.1097/00001703-200010000-00006

[22] Berker, B., Mahdavi, A., Shahmohamady, B. and Nezhat, C. (2005) Role of Laparoscopic Surgery in Infertility. Middle East Fertility Society Journal, 10, 94-104.

[23] Bruhat, M.A., Mage, G., Pouly, J.L., Manhes, H., Canis, M. and Wattiez, A. (1989) Coelioscopie opératoire. Medsi/ McGraw-Hill, Healthcare Group, Paris, 215 p.

[24] Kasia, J.M., Raiga, J., Doh, A.S., Biouele, J.M., Pouly, J.L., Kwiatkowski, F., et al. (1997) Laparoscopic Fimbrioplasty and Neosalpingostomy. Experience of the Yaoundé General Hospital, Cameroon (Report of 194 Cases). The European Journal of Obstetrics and Gynecology and Reproductive Biology, 73, 71-77. http://dx.doi.org/10.1016/S0301-2115(96)02674-7 